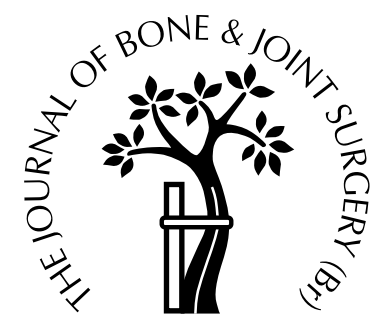

\title{
Outcome of ulnar neurolysis during post-traumatic reconstruction of the elbow
}

\author{
Michael D. McKee, Jesse B. Jupiter, Gae Bosse, Laura Goodman \\ From the University of Toronto, Canada and Harvard University, Boston, USA
}

W e performed ulnar nerve neurolysis and transposition during reconstructive operations on 20 consecutive patients ( 21 elbows) with neuropathy after the failure of primary treatment of elbow fractures. There were 11 men and nine women with a mean age of $\mathbf{4 8 . 3}$ years. Preoperatively, four elbows were in McGowan stage I, seven in stage II and ten in stage III and the mean Gabel and Amadio ulnar nerve score was 3.2. At a mean follow-up of 32.1 months (24 to 67) we performed comprehensive neurological, functional, electrophysiological and outcome assessments.

Patient satisfaction was high with good pain relief and restoration of hand strength and dexterity. The mean Gabel and Amadio score had improved to 6.5, an improvement of 3.3. There were one excellent, 16 good, 2 fair and 2 poor results; both of the last were due to failure of the underlying elbow reconstruction. Even for advanced stage-II and stage-III lesions we achieved good function, return of intrinsic power, and a high rate of patient satisfaction.

J Bone Joint Surg [Br] 1998;80-B:100-5.

Received 27 March 1997; Accepted 7 May 1997

The cubital tunnel is narrow and the ulnar nerve may be injured in fractures around the elbow ${ }^{1-3}$ by direct injury, impaction of bony fragments or iatrogenic damage during internal fixation. ${ }^{3,4}$ Subsequent scarring and fibrosis may

M. D. McKee, MD, FRCS C, Assistant Professor

Upper Extremity Reconstructive Service, Division of Orthopaedics, Department of Surgery, St Michael's Hospital, University of Toronto,

Toronto, Canada.

J. B. Jupiter, MD, Director

Orthopaedic Hand Service

G. Bosse, MHA, OTR/L, Certified Hand Therapist

Department of Occupational Therapy

L. Goodman, BA, Research Assistant

Orthopaedic Trauma Service

Massachusetts General Hospital, Boston, Massachusetts, USA.

Correspondence should be sent to Dr M. D. McKee at 55 Queen Street East, Suite 800, Toronto, Ontario, Canada M5C IR6.

(C)1998 British Editorial Society of Bone and Joint Surgery 0301-620X/98/17822 \$2.00

100 cause compression of the nerve, especially if there is prolonged immobilisation or elbow stiffness. ${ }^{5-7}$

Severe ulnar neuropathy is sometimes the most disabling result of the failure of primary treatment of an injured elbow, but opinion varies considerably in regard to treatment. Ulnar neurolysis and transposition have been described as isolated procedures for cubital tunnel syndrome of various causes, ${ }^{5,8-10}$ but there is little information on the results of neurolysis performed at the time of secondary reconstruction of the elbow. It is widely thought that in advanced lesions with intrinsic muscle wasting the prognosis for recovery of the nerve is poor, ${ }^{6,7,9,11}$ especially in older patients. Previous assessments have concentrated on the effects on the nerve or the joint without full consideration of function in everyday life. ${ }^{12-15}$

We report 20 consecutive patients with post-traumatic ulnar neuropathy who had comprehensive, multidisciplinary assessment after neurolysis and anterior transposition of the ulnar nerve at the time of later reconstruction of injured elbows.

\section{Patients And Methods}

Between 1985 and 1992, 60 patients had reconstructive surgery performed by the senior author (JBJ) for the late effects of injury to the elbow. Of these, 20 (21 elbows) had neurolysis and transposition of the ulnar nerve as part of the procedure; these are the basis of the study. We defined ulnar neuropathy as subjective symptoms in the distribution of the ulnar nerve in the hand and forearm (21 elbows), weakness in the muscles of the hand and forearm innervated by the ulnar nerve (17 elbows) and increased twopoint discrimination in the sensory distribution of the nerve in the hand (19 elbows). All patients had at least two of these three features.

We excluded patients who had ulnar neuropathy and elbow pathology which was not secondary to injury, those who did not have objective signs of ulnar neuropathy before their elbow reconstruction and those who had isolated ulnar neuropathy after injury and who then had ulnar neurolysis and transposition alone.

There were 11 men and nine women with a mean age of 48 years (23 to 75 ). The primary injury of the elbow was an intra-articular fracture of the distal humerus in 14, fracture- 
Table I. Details and results in the 20 patients (21 elbows)

\begin{tabular}{|c|c|c|c|c|c|c|c|c|c|c|c|c|}
\hline \multirow[b]{2}{*}{ Case } & \multirow{2}{*}{$\begin{array}{l}\text { Age } \\
(\mathbf{y r})\end{array}$} & \multirow[b]{2}{*}{ Gender } & \multirow{2}{*}{$\begin{array}{l}\text { Original } \\
\text { injury }\end{array}$} & \multirow[b]{2}{*}{ Procedures } & \multirow{2}{*}{$\begin{array}{l}\text { Reconstr } \\
\text { delay } \\
\text { (mth) }\end{array}$} & \multicolumn{2}{|c|}{ McGowan } & \multicolumn{2}{|c|}{ Gabel \& Amadio } & \multirow{2}{*}{$\begin{array}{l}\text { Reconstr op } \\
\text { indication }\end{array}$} & \multirow{2}{*}{$\begin{array}{l}\text { Follow-up } \\
\text { (mth) }\end{array}$} & \multirow{2}{*}{$\begin{array}{l}\text { Satisfaction } \\
\text { VAS* }\end{array}$} \\
\hline & & & & & & Preop & Postop & Preop & Postop & & & \\
\hline 1 & 63 & $\mathrm{M}$ & Distal hum fract & 1 & 2 & I & $\mathrm{I}$ & 5 & 7 & TEA $\dagger$ & 24 & 6 \\
\hline 2 & 62 & $\mathrm{~F}$ & Distal hum fract & 2 & 18 & II & $\mathrm{I}$ & 2 & 8 & Nonunion & 30 & 9 \\
\hline 3 & 54 & $\mathrm{~F}$ & Distal hum fract & 1 & 6 & III & I & 1 & 6 & Nonunion & 24 & 9 \\
\hline 4 & 34 & $\mathrm{~F}$ & Olecranon fract & 3 & 14 & II & I & 4 & 8 & Debridement & 67 & 9 \\
\hline 5 & 55 & $\mathrm{~F}$ & Distal hum fract & 1 & 1 & III & I & 1 & 6 & Nonunion & 24 & 9 \\
\hline 6 & 35 & M & Distal hum fract & 2 & 96 & II & $\mathrm{I}$ & 4 & 8 & Malunion & 24 & 10 \\
\hline 7 & 58 & M & Distal hum fract & 1 & 12 & III & $\mathrm{I}$ & 3 & 7 & Malunion & 36 & 10 \\
\hline 8 & 73 & M & Distal hum fract & 1 & 12 & III & $\mathrm{I}$ & 4 & 7 & Nonunion & 36 & 10 \\
\hline 9 & 55 & $\mathrm{~F}$ & Distal hum fract & 1 & 12 & I & I & 5 & 8 & Nonunion & 42 & 6 \\
\hline 10 & 53 & $\mathrm{~F}$ & Distal hum fract & 1 & 6 & III & I & 2 & 8 & Elbow release & 43 & 10 \\
\hline 11 & 48 & $\mathrm{~F}$ & Distal hum fract & 2 & 6 & III & $\mathrm{I}$ & 4 & 6 & Nonunion & 24 & 8 \\
\hline 12 & 36 & M & Fract-disloc elbow & 3 & 12 & III & $\mathrm{I}$ & 3 & 6 & $\begin{array}{l}\text { Elbow } \\
\text { debridement }\end{array}$ & 24 & 6 \\
\hline 13 & 23 & M & Distal hum fract & 2 & 168 & II & $\mathrm{I}$ & 5 & 7 & $\begin{array}{l}\text { Elbow } \\
\text { debridement }\end{array}$ & 24 & 8 \\
\hline 14 & 34 & M & Fract-disloc elbow & 4 & 96 & III & II & 2 & 2 & TEA & 24 & $1 \neq$ \\
\hline 15 & 36 & M & $\begin{array}{l}\text { Soft-tissue injury, } \\
\text { infection }\end{array}$ & 12 & 18 & II & II & 2 & 3 & Elbow release & 24 & 5 \\
\hline $\begin{array}{r}16 \mathrm{R} \\
\mathrm{L}\end{array}$ & 40 & M & $\begin{array}{l}\text { Fract-disloc elbow } \\
\text { Fract-disloc elbow }\end{array}$ & $\begin{array}{l}2 \\
2\end{array}$ & $\begin{array}{r}6 \\
18\end{array}$ & $\begin{array}{l}\text { I } \\
\text { II }\end{array}$ & $\begin{array}{l}\text { I } \\
\text { I }\end{array}$ & $\begin{array}{l}4 \\
2\end{array}$ & $\begin{array}{l}6 \\
6\end{array}$ & Elbow release & 24 & $\begin{array}{l}10 \\
10\end{array}$ \\
\hline 17 & 54 & $\mathrm{~F}$ & Fract-disloc elbow & 1 & 12 & II & $\mathrm{I}$ & 5 & 7 & Nonunion & 30 & 10 \\
\hline 18 & 70 & M & Distal hum fract & 1 & 30 & III & II & 2 & 6 & Nonunion & 48 & 8 \\
\hline 19 & 84 & $\mathrm{~F}$ & Distal hum fract & 2 & 36 & III & II & 2 & 6 & TEA & 24 & $5 \neq$ \\
\hline 20 & 62 & $\mathrm{~F}$ & Distal hum fract & 1 & 12 & I & I & 5 & 9 & Nonunion & 36 & 10 \\
\hline
\end{tabular}

dislocation of the elbow in five, fracture of the olecranon in one, and a crush injury in one (Table I). The median period from the initial injury to the reconstructive procedure was 12 months (1 to 168) in 19 patients. In one patient (case 13) reconstruction was performed 14 years after the original injury. Post-traumatic disorders included underlying periarticular malunion or ununited fracture (11), post-traumatic arthritis (7), periarticular heterotopic bone (6) and softtissue contracture (5).

Motor function was assessed according to the Medical Research Council (MRC) scale. ${ }^{16}$ The muscles tested included the flexor carpi ulnaris, adductor pollicis, abductor digiti quinti, and the first dorsal interosseous muscle. Seven patients had electrophysiological testing before referral and all showed alteration in both sensory conduction velocity and EMG.

We used two clinical staging systems to assess the degree of dysfunction of the ulnar nerve to try to distinguish the results of ulnar neurolysis from the overall elbow reconstruction. The classification of McGowan ${ }^{11}$ defines a minimal lesion with no detectable motor weakness of the hand as grade I, an intermediate lesion (weakness) as grade II and a severe lesion with paralysis of one or more of the ulnar intrinsic muscles as grade III. The system of Gabel and Amadio $^{5}$ for evaluation of the outcome of revision surgery scores subjective complaints of pain, objective sensory tests, and motor tests with a point score from 0 to 3 for each. A normal elbow without symptoms scores 9 points.

Operative technique. We used an extensive exposure to reconstruct the intra-articular pathology and to mobilise and perform neurolysis of the ulnar nerve. Because of severe scarring and fibrosis around the elbow the nerve was usually identified proximally beneath the edge of the triceps muscle. In five patients the nerve had been transposed anteriorly at a previous surgical intervention and was found to be encased in periarticular fibrosis, often trapped by bony fragments, heterotopic bone formation, metal implants or suture material. No nerve had been transected.

We performed external neurolysis using either loupe or microscopic magnification with microsurgical techniques and instrumentation. Dissection of the nerve was from proximal to distal, starting 6 to $8 \mathrm{~cm}$ above the medial epicondyle. To avoid focal constriction of the nerve, the distal half of the medial intramuscular septum was excised. The nerve was dissected for 5 to $6 \mathrm{~cm}$ into the flexor pronator muscle group distal to the medial epicondyle, 
taking care to protect and identify the motor branches to the flexor carpi ulnaris. At the conclusion of the operation, the nerve was placed subcutaneously anterior to the medial epicondyle free from any pressure.

All 20 patients (21 elbows) returned for assessment by a multidisciplinary team which included an independent orthopaedic surgeon, a certified occupational hand therapist and a research nurse. The mean follow-up was 32.1 months (24 to 67).

Assessment included a complete history and physical examination and completion of a satisfaction questionnaire and health status surveys (Nottingham Health Profile, ${ }^{17-19}$ SF-36 $6^{20,21}$ ). Physical examination included inspection for signs of ulnar neuropathy and two-point discrimination. Grip and pinch strength were measured using Jamar grip and pinch-strength dynamometers. We also performed the Semmes-Weinstein monofilament test, ${ }^{22}$ the hand function test of Jebsen et $\mathrm{al}^{23}$ and a nerve-conduction test using a Nervepace digital neurometer. ${ }^{24}$

Patient satisfaction was recorded on a visual analogue scale to evaluate satisfaction with surgery $(0=$ completely unsatisfied, $10=$ completely satisfied), with similar scales to assess pain, weakness and numbness, with 0 being none, 5 moderate and 10 severe. The predominant preoperative symptom was documented. Patients were specifically asked if they would have the surgery again in similar circumstances. The use of analgesics, symptoms at night, return to employment and any new postoperative symptoms were noted.

Statistical analysis. We assessed statistical correlation between outcomes by the Pearson correlation coefficient and comparison of pre- and postoperative differences in mean values by a paired two-tailed $t$-test. A level of $\mathrm{p}<0.05$ was considered to be statistically significant.

\section{$\underline{\text { Results }}$}

All 21 elbows had at least one previous operation; 11 patients had additional surgery ranging from two to 12 procedures.

Patient satisfaction. Patient satisfaction was high with a mean score of 8.0 (4 to 10). The mean pain score was 3.1 ( 0 to 8$)$, the mean weakness score 3.5 (0 to 7 ) and the mean numbness score was 4.1 (0 to 8 ). Night pain and/or numbness and tingling was completely relieved in 16 patients and reduced to negligible levels in the other four. All patients have been taking narcotic analgesics preoperatively. Postoperatively, 11 patients had no pain attributable to their ulnar nerve, seven had mild pain which did not require any analgesics and two had constant pain that required regular analgesia. Eighteen of the 20 patients said that they would have this surgery again if indicated. Fifteen patients were able to return to their preinjury occupations or level of function, three were forced to change occupations but were still gainfully employed, and two were unable to return to active employment.
Ulnar neuropathy. The mean preoperative Gable and Amadio score was 3.2 points ( 1 to 5) (Table I); postoperatively, it was 6.5 . The mean improvement per patient was 3.3 points ( 0 to 6 ). There were one excellent, 16 good, 2 fair and 2 poor results. Both poor results were in patients with failure of the underlying elbow reconstruction. Preoperatively, four limbs were in McGowan grade I, seven in stage II and ten in stage III. Postoperatively, 17 were in stage I (no detectable weakness), four in stage II and none in stage III.

Grip/pinch strength. Examination with the Jamar dynamometer showed grip strengths which averaged $67 \%$ of the contralateral side. Lateral pinch strength averaged $71 \%$ and tip pinch strength $73 \%$ of the unaffected side. The one patient with bilateral elbow problems was not included. Of the 17 patients with intrinsic muscle weakness, paralysis or wasting, 12 recovered grade-5 power, four grade 4, and one remained at grade 3 . No patient had a permanent decrease in intrinsic muscle strength as the result of the procedure (Table II).

Semmes-Weinstein monofilament test. All patients except case 16, with bilateral injuries, had normal sensation in the contralateral ulnar nerve as measured by the monofilament test on the volar side of the little finger. Nine patients had normal sensation, eight had diminished light touch, one had diminished protective sensation and three patients had loss of protective sensation. Overall, the mean two-point discrimination was $7 \mathrm{~mm}$. In the four patients with diminished or lost protective sensation it was $13 \mathrm{~mm}$, in the remainder $6 \mathrm{~mm}(\mathrm{p}=0.002)$. There was a high degree of correlation $(r=0.7630, p=0.0001)$ between the Semmes-Weinstein test and the measured two-point discrimination (Table II). Jebsen's hand function test. The mean score was $133 \%$ (94 to 316) of standardised mean test times. This meant that the average patient required $33 \%$ longer to perform a similar manual task with the involved limb than a control group. Two patients, both with failure of the underlying elbow reconstruction, had increased scores of $266 \%$ and $316 \%$. The time taken to complete the test had a strong negative correlation with grip $(\mathrm{r}=-0.7146, \mathrm{p}=0.001)$, lateral pinch $(\mathrm{r}=-0.6342, \mathrm{p}=0.004)$ and tip pinch $(\mathrm{r}=$ $-0.6179, p=0.005)$ strengths. This indicates that increasing grip or pinch strength decreases the time required to perform the test. The time taken to complete the test correlated positively with increased scores in difficulty in completing tasks of daily living of the Nottingham Health Profile ( $\mathrm{r}=0.8784, \mathrm{p}=0.0001)$ (Table II).

SF-36 health survey. The mean 'global' SF-36 score was only 68.2 , indicating that these patients had not returned to normal health (Table III). According to the SF-36 score, 19 patients still felt some degree of physical limitation in the involved arm, but only three patients reported a loss of selfimage.

Nottingham health profile. The results of part one included a mean reduction in physical mobility of $16 \%$, an increase in pain of $21 \%$, an increase in emotional reaction 
Table II. Results of specialist tests

\begin{tabular}{|c|c|c|c|c|c|c|c|}
\hline \multirow[b]{2}{*}{ Case } & \multirow{2}{*}{$\begin{array}{l}\text { Grip } \\
\text { strength }\end{array}$} & \multicolumn{2}{|c|}{ Pinch strength } & \multirow{2}{*}{$\begin{array}{l}\text { Semmes- } \\
\text { Weinstein }\end{array}$} & \multirow{2}{*}{$\begin{array}{l}\text { NCV* } \\
\text { Nerpace }\end{array}$} & \multirow{2}{*}{$\begin{array}{l}\text { Jebsen } \\
(\%)\end{array}$} & \multirow{2}{*}{$\begin{array}{l}\text { 2-pt } \\
(\mathbf{m m})\end{array}$} \\
\hline & & Lateral & Tip & & & & \\
\hline 1 & 58 & 45 & 82 & 3.22 & 90 & 120 & 7 \\
\hline 2 & 57 & 78 & 83 & 3.22 & 80 & 113 & 8 \\
\hline 3 & 62 & 52 & 57 & 3.22 & 91 & 115 & 7 \\
\hline 4 & 97 & 73 & 120 & 2.83 & 80 & 104 & 5 \\
\hline 5 & 50 & 67 & 50 & 3.84 & 58 & 139 & 8 \\
\hline 6 & 100 & 75 & 64 & 2.83 & 84 & 103 & 5 \\
\hline 7 & 102 & 103 & 105 & 2.83 & 92 & 121 & 5 \\
\hline 8 & 70 & 83 & 81 & 3.22 & 93 & 94 & 6 \\
\hline 9 & 50 & 76 & 67 & 2.83 & 80 & 149 & 5 \\
\hline 10 & 107 & 140 & 143 & 3.22 & 94 & 107 & 8 \\
\hline 11 & 61 & 52 & 46 & 3.22 & 75 & 120 & 10 \\
\hline 12 & 48 & 60 & 63 & 3.22 & 90 & 107 & 7 \\
\hline 13 & 85 & 83 & 79 & 2.83 & 90 & 134 & 5 \\
\hline 14 & 12 & 18 & 20 & 3.84 & 64 & 266 & $>15$ \\
\hline 15 & 10 & 20 & 25 & 3.84 & 65 & 316 & 10 \\
\hline $16 \mathrm{R}$ & - & - & - & 2.44 & & 143 & 6 \\
\hline $\mathrm{L}$ & - & - & - & 2.44 & & 121 & 5 \\
\hline 17 & 95 & 95 & 90 & 2.83 & 80 & 140 & 6 \\
\hline 18 & 60 & 75 & 70 & 3.22 & 70 & 110 & 8 \\
\hline 19 & 55 & 60 & 55 & 3.61 & 62 & 115 & 8 \\
\hline 20 & 95 & 98 & 90 & 2.44 & 70 & 105 & 5 \\
\hline
\end{tabular}

* nerve-conduction velocity

Table III. SF-36 scores in 20 patients

\begin{tabular}{|c|c|c|c|c|c|c|c|c|}
\hline Case & $\begin{array}{l}\text { Physical } \\
\text { function }\end{array}$ & $\begin{array}{l}\text { Physical } \\
\text { role }\end{array}$ & Pain & $\begin{array}{l}\text { General } \\
\text { health }\end{array}$ & Vitality & $\begin{array}{l}\text { Social } \\
\text { function }\end{array}$ & $\begin{array}{l}\text { Emotional } \\
\text { role }\end{array}$ & $\begin{array}{l}\text { Mental } \\
\text { health }\end{array}$ \\
\hline 1 & 50 & 0 & 52 & 45 & 0 & 0 & 0 & 0 \\
\hline 2 & 85 & 100 & 84 & 92 & 73 & 100 & 100 & 100 \\
\hline 3 & 85 & 100 & 72 & 100 & 80 & 100 & 100 & 92 \\
\hline 4 & 100 & 100 & 100 & 95 & 80 & 100 & 100 & 100 \\
\hline 5 & 55 & 25 & 74 & 92 & 80 & 100 & 100 & 92 \\
\hline 6 & 85 & 75 & 51 & 77 & 60 & 100 & 67 & 72 \\
\hline 7 & 65 & 50 & 51 & 42 & 25 & 50 & 100 & 72 \\
\hline 8 & 90 & 100 & 100 & 75 & 80 & 100 & 100 & 92 \\
\hline 9 & 80 & 100 & 74 & 72 & 75 & 75 & 100 & 72 \\
\hline 10 & 85 & 100 & 100 & 77 & 55 & 100 & 100 & 76 \\
\hline 11 & 87.5 & 0 & 74 & 72 & 60 & 100 & 100 & 92 \\
\hline 12 & 65 & 100 & 31 & 67 & 55 & 25 & 0 & 56 \\
\hline 13 & 85 & 100 & 80 & 92 & 80 & 100 & 100 & 88 \\
\hline 14 & 25 & 50 & 22 & 15 & 35 & 25 & 0 & 32 \\
\hline 15 & 40 & 0 & 22 & 72 & 25 & 50 & 0 & 40 \\
\hline 16 & 45 & 0 & 52 & 57 & 65 & 75 & 100 & 84 \\
\hline 17 & 85 & 100 & 80 & 100 & 30 & 37.5 & 0 & 64 \\
\hline 18 & 95 & 100 & 100 & 100 & 100 & 100 & 100 & 100 \\
\hline 19 & 50 & 75 & 41 & 50 & 35 & 75 & 33.3 & 68 \\
\hline 20 & 50 & 75 & 74 & 72 & 20 & 37.5 & 66.7 & 64 \\
\hline Mean & 70.4 & 67.5 & 62.7 & 73.2 & 55.9 & 74.5 & 68.3 & 72.8 \\
\hline
\end{tabular}

Table IV. Nottingham Health Profile scores in 20 patients

\begin{tabular}{ll}
\hline Physical mobility & $16 \%$ decrease \\
Pain & $21 \%$ increase \\
Emotional reaction & $19 \%$ increase \\
Energy level & $21 \%$ decrease \\
Sleep & $31 \%$ decrease \\
Social isolation & $12.5 \%$ increase \\
Global health & $21 \%$ decrease \\
\hline
\end{tabular}

of $19 \%$, a decrease in energy level of $21 \%$, a decrease in sleep of $31 \%$, and an increase in social isolation of $12.5 \%$. Overall, there was a global decrease of $21 \%$ (Table IV). Response to part two indicated that five patients had no difficulty with any task, 11 had difficulty with only one or two tasks, and four had difficulty with three or more tasks. Two patients, both with failure of the underlying elbow reconstruction, had difficulty with all seven tasks. On aver- 
age, patients reported difficulty performing $31 \%$ of the tasks related to their state of health, with inability to perform household chores and hobbies being the most common positive responses.

Electrophysiological testing. Postoperatively, the mean motor nerve-conduction velocity was $31.8 \mathrm{~m} / \mathrm{s}$ on the affected side and $39.9 \mathrm{~m} / \mathrm{s}$ on the unaffected side. This represents a mean decrease in nerve-conduction velocity of approximately $20.4 \%$ compared with the normal contralateral side (Table II).

\section{Discussion}

Ulnar neuropathy is one of the most disabling aspects of the failure of primary treatment of periarticular elbow injuries, ${ }^{1-4}$ but there is little information about treatment and outcome. Patients with advanced neuropathy including wasting of intrinsic muscles or paralysis are thought to have a poor outcome. ${ }^{6,7,9-11}$ Most reports include such patients in larger series which have had ulnar nerve neurolysis and transposition done in isolation for cubital tunnel syndrome for a variety of causes. ${ }^{5,8-10}$ Our series represents a unique group of patients who required ulnar neurolysis at the time of extensive post-traumatic elbow reconstruction. This aspect has not been previously reported.

Previous studies by Geutjens et $\mathrm{al}^{25}$ and Tsujino et $\mathrm{al}^{26}$ have shown the patients with ulnar neuropathy, either of spontaneous onset or associated with osteoarthritis of the elbow, can be treated surgically by simple decompression and release of the nerve rather than transposition. As with our technique a common feature is the complete release of the nerve from any constricting or enveloping fascia, fibrosis or bony impingement. One of the advantages of the limited procedure which they describe is the decreased amount of soft-tissue dissection. In our patients, this dissection had usually been done before as part of the reconstruction of the elbow. Thus, transposition of the nerve added little to the procedure. In many of our patients the presence of metal implants made anterior transposition of the nerve preferable.

Our findings suggest that good functional results, return of intrinsic muscle power and a high rate of patient satisfaction can be achieved after ulnar neurolysis at the time of elbow reconstruction, even in stage-II and stage-III lesions with intrinsic muscle weakness or paralysis. We always performed complete release of the nerve and transfer to a tension-free position. In addition, the successful reconstruction of the elbow allowed early postoperative movement; this helps to prevent the scarring and fibrosis around the nerve seen after previous procedures with prolonged immobilisation in a cast. This is confirmed by the poor neurological outcome associated with the failure of the elbow reconstruction in two of our cases. Early movement has been shown to be beneficial to the repair of periarticular nerve injuries. $^{27}$

Most of our patients had successful objective and sub- jective outcomes. Patient satisfaction was high and the use of analgesics was decreased or eliminated in most, as was night pain or paraesthesiae. Improvement in muscle strength correlated with favourable completion times on Jebsen's hand function test. Nerve-conduction velocity postoperatively was similar to that after the release of other entrapment neuropathies. ${ }^{9,24,28}$ Our mean improvement in outcome score of 3.3 points per patient according to the system of Gabel and Amadio ${ }^{5}$ correlated well with the mean score for nerve function and with the 2.9 points improvement per patient seen in their series of 30 patients who had revision for failed decompression.

Our patients had general improvement, but did not feel that they had a 'normal' limb. Measurement of functional outcome by the SF-36 health status survey and the Nottingham health profile is more sensitive for revealing residual disability or functional deficits than the traditional or objective measures usually used to assess outcome. ${ }^{17-21}$ In our series, $95 \%$ of the patients still felt some degree of physical limitation in the involved upper limb. We consider that assessment of all such patients would be enhanced by the inclusion of special measures of functional outcome. Most of our patients were able to return to active employment, but significant impairment in the performance of healthrelated activities was noted by the NHP survey.

Our study has three potential weaknesses. The first is the difficulty in differentiating between the nerve and underlying joint problem. Since the two are interrelated, such a distinction may be artificial, but we have used some criteria that are more specific for nerve and hand function in our assessment. Secondly, there is a lack of preoperative data on EMG or nerve-conduction velocity in our patients, but the clear clinical diagnosis of ulnar neuropathy in most of our cases made these tests unnecessary. Thirdly, our study would have been enhanced by the addition of preoperative data on general health status, which would have allowed a more accurate assessment of the effect of our procedure on the patient's overall health.

No benefits in any form have been received or will be received from a commercial party related directly or indirectly to the subject of this article.

\section{References}

1. Bryan RS. Fractures about the elbow in adults. AAOS: Instr Course Lect 30:200. St Louis, C. V. Mosby, Co, 1981.

2. Lecestre R. Round table on fractures of the lower end of the humerus. Orthop Trans 1980;4:123.

3. Wang KC, Shih HN, Hsu KY, Shih CH. Intercondylar fractures of the distal humerus: routine anterior subcutaneous transposition of the ulnar nerve in a posterior operative approach. J Trauma 1994;36: 770-3.

4. Wright PE, Jobe MT. Peripheral nerve injuries. In: Crenshaw AH, ed. Campbell's operative orthopaedics. St. Louis: Mosby Year Book, 1987:2215.

5. Gabel GT, Amadio PC. Reoperation for failed decompression of the ulnar nerve in the region of the elbow. J Bone Joint Surg [Am] 1990; 72-A:213

6. Amadio PC, Gabel GT. Treatment and complications of failed decompression of the ulnar nerve at the elbow. In: Gelberman RM, ed. Operative nerve repair and reconstruction. Philadelphia: JB Lippincott, 1991;1107-19. 
7. Seddon H. Surgical disorders of the peripheral nerves. Baltimore: Williams and Wilkins, 1972.

8. Campbell JB, Post KD, Morantz RA. A technique for relief of motor and sensory deficits occurring after anterior ulnar transposition. J Neurosurg 1974;40:405-9.

9. Dellon AL. Review of treatment results for ulnar nerve entrapment at the elbow. J Hand Surg 1989;14-A:688-700.

10. Broudy AS, Leffert RD, Smith RJ. Technical problems with ulnar nerve transposition at the elbow: findings and results of reoperation. J Hand Surg Am 1978;3:85-9.

11. McGowan AJ. The results of transposition of the ulnar nerve for traumatic ulnar neuritis. J Bone Joint Surg [Br] 1950;32-B:293-301.

12. Barrios C, Ganoza C, de Pablos J, Canadell J. Posttraumatic ulnar neuropathy versus nontraumatic cubital tunnel syndrome: clinical features and response to surgery. Acta Neurochir Wien 1991; 110:44-8.

13. Davidson AJ, Horwitz MT. Late or tardy ulnar nerve paralysis. J Bone Joint Surg 1935; 17:844-56.

14. Eaton RG, Crowe JF, Parkes JC. Anterior transposition of the ulnar nerve using a non-compressing fasciodermal sling. J Bone Joint Surg [Am] 1980;62-A:820-5.

15. Gay J, Love JG. Diagnosis and treatment of tardy paralysis of the ulnar nerve. J Bone Joint Surg 1947;29:1087-97.

16. Medical Research Council. Aids to examination of the peripheral nervous system. Memorandum No. 45, London. HMSO, 1976.

17. Hunt SM, McKenna SP, McEwen J, et al. A quantitative approach to perceived health status: a validation study. J Epidemiol Community Health 1980;34:281-6.

18. Hunt SM, McKenna SP, McEwen J, Williams J, Papp E. The Nottingham Health profile: subjective health status and medical consultations. Soc Sci Med A 1981;15:221-9.
19. Nilsson LT, Franzén H, Carlsson ÅS, Önnerfält R. Early radiographic loosening impairs the function of a total hip replacement: the Nottingham Health profile of 49 patients at five years. $J$ Bone Joint Surg [Br] 1994;76-B:235-9.

20. Ware JE, Snow KK, Kosinski M, Gandek B. SF-36 Health Survey Manual and interpretation guide. Boston: New England Medical Center, The Health Institute, 1993.

21. Kraemer J, Schemitsch EH, Lever J, et al. Functional outcome of thoraco-lumbar burst fractures without neurological deficit. J Orthop Trauma 1996;10:541-4.

22. Bell-Krotoski J, Weinstein S, Weinstein C. Testing sensibility, including touch-pressure, two-point discrimination, point localization, and vibration. $J$ Hand Ther 1993;6:114-23.

23. Jebsen RH, Taylor N, Trieschmann RB, et al. An objective and standardized test of hand function. Arch Phys Med 1969;50:311-9.

24. Feierstein MS. The performance and usefulness of nerve conduction studies in the orthopaedic office. Orthop Clin North Am 1988; 19:859-66.

25. Geutjens GG, Langstaff RJ, Smith NJ, et al. Medial epicondylectomy or ulnar-nerve transposition for ulnar neuropathy at the elbow? J Bone Joint Surg [Br] 1996;78-B:777-9.

26. Tsujino A, Itoh Y, Hayashi K, Uzawa M. Cubital tunnel reconstruction for ulnar neuropathy in osteoarthritic elbows. J Bone Joint Surg [Br] 1997;79-B:390-3.

27. Kim HKW, Turley GB, Jay V, et al. The effects of postoperative continuous passive motion on peripheral nerve repair and regeneration: an experimental investigation in the rabbit. Orthop Trans 1992;16:397-8.

28. Dellon AL, Schlegel RW, MacKinnon SE. Validity of nerve conduction velocity studies after anterior transposition of the ulnar nerve. J Hand Surg Am 1987;12:700-3. 